\title{
Functional titania-silica/chlorophyllin hybrids: design, fabrication, comprehensive physicochemical characteristic and photocatalytic test
}

\author{
Katarzyna Siwińska-Ciesielczyk ${ }^{1} \cdot$ Olga Bartlewicz $^{1,2} \cdot$ Przemysław Bartczak $^{1} \cdot$ Adam Piasecki $^{3} \cdot$ Teofil Jesionowski $^{1}$
}

Received: 20 September 2018 / Revised: 14 January 2019 / Accepted: 7 February 2019 / Published online: 19 February 2019

(c) The Author(s) 2019

\begin{abstract}
Chlorophyllin (which was used as sensitizer) was adsorbed onto a synthetic titania-silica oxide system, prepared via a sol-gel method. It was investigated how the adsorption process was affected by the initial concentration of chlorophyllin and the contact time of the solution. The physicochemical and structural properties of the inorganic support were comprehensively analyzed, including determination of the dispersive properties and morphology of the material (particle size distribution, SEM image), crystalline structure (XRD), chemical composition (EDS), parameters of the porous structure (low-temperature $\mathrm{N}_{2}$ sorption) and thermal stability (TGA/DTA). The effectiveness of chlorophyllin adsorption on $\mathrm{TiO}_{2}-\mathrm{SiO}_{2}$ was examined by Fourier transform infrared spectroscopy. The degree of coverage of the inorganic support with chlorophyllin was calculated from the Berendsen and de Golan equation based on BET and elemental analysis results. The kinetics of the adsorption of chlorophyllin onto the synthetic titania-silica oxide system were also determined. The experimental data correspond directly to a pseudo-second-order model. Moreover, the photocatalytic activity of selected $\mathrm{TiO}_{2}-\mathrm{SiO}_{2} /$ chlorophyllin hybrids with respect to the decomposition of C.I. Basic Violet 10 dye was investigated. It was found that the titania-silica hybrids conjugated with chlorophyllin exhibited higher photocatalytic activity in the degradation of C.I. Basic Violet 10 than the pure $\mathrm{TiO}_{2}-\mathrm{SiO}_{2}$ material. Moreover, the kinetics of the photocatalytic degradation of selected organic compound was determined based on the Langmuir-Hinshelwood equation, assuming the pseudo-first-order reaction.
\end{abstract}

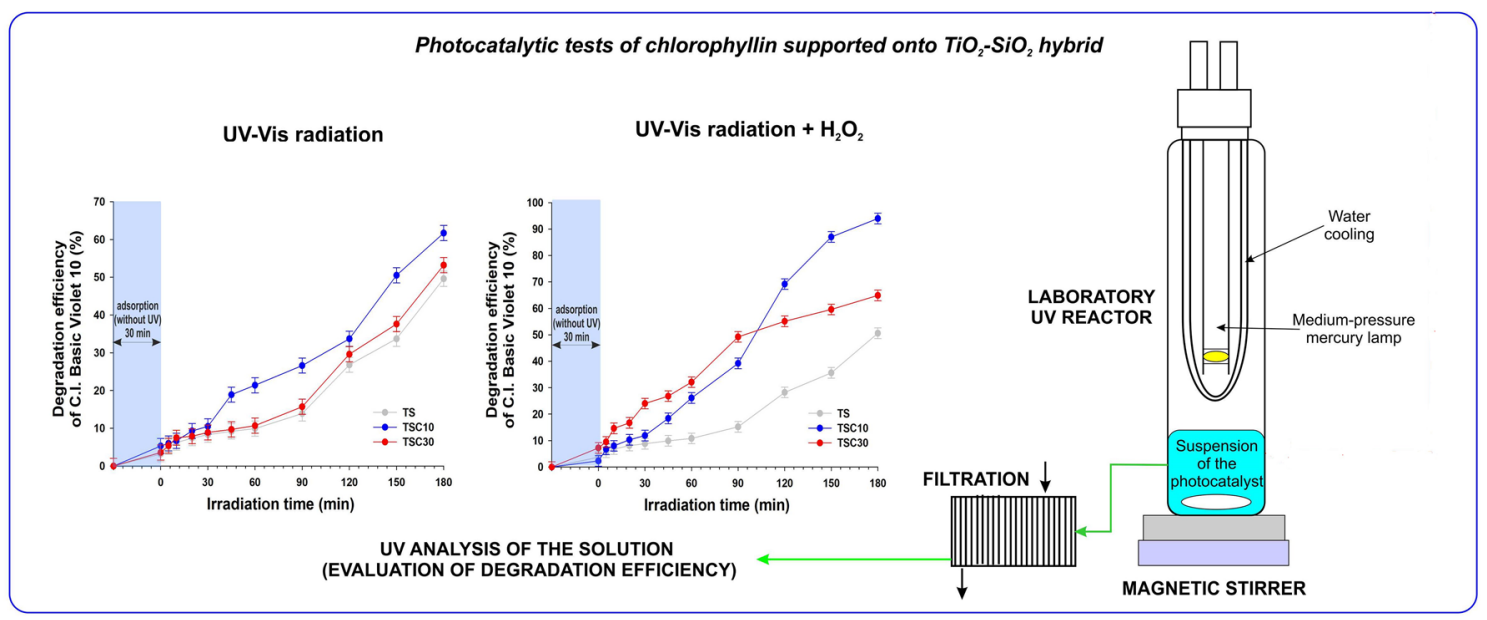

Keywords Chlorophyllin $\cdot$ Titania-silica $\cdot$ Hybrid system $\cdot$ Sol-gel method $\cdot$ Adsorption $\cdot$ Photocatalysis

Electronic supplementary material The online version of this article (https://doi.org/10.1007/s10450-019-00035-3) contains supplementary material, which is available to authorized users.

Extended author information available on the last page of the article

\section{Introduction}

During the last few years, there has been a dynamic increase of interest in studies focused on the selection of an appropriate synthesis method or modification of titanium dioxide as 
well as the selection of proper components which together with $\mathrm{TiO}_{2}$ form advanced, multifunctional hybrid materials with strictly defined physicochemical properties, especially including photocatalytic activity (Chen and Mao 2007; Kumar and Rao 2017; Nolan et al. 2016; Fujishima et al. 2008).

The outstanding and unique optical and physicochemical properties of titanium dioxide, such as the ability to absorb destructive ultraviolet radiation, chemical and thermal stability, biocompatibility, insolubility and non-toxicity, contribute to the fact that this oxide is used in many branches of the industry. Titanium dioxide is widely used in the paint and varnish industry, environmental protection, electronic devices, gas sensors and solar cells. In addition, it is also utilized, although to a lesser extent, in other areas of the market, including the textile, pharmaceutical, cosmetics, cement or rubber industries (Chen and Mao 2007; Winkler 2013; Braun 1997).

The available scientific literature states that titanium dioxide is one of the most effective photocatalysts used in the decomposition processes of a very wide range of compounds which contaminate the environment, removal of microorganisms and self-cleaning systems. Alongside the advantages of titanium dioxide commonly used as a catalyst, such as: relatively low price, high oxidation potential, non-toxicity, and high chemical stability, there are several disadvantages, which include limited spectral range of photoresponse, low quantum efficiency of the process and fast recombination of charge carriers (Chen and Mao 2007; Fujishima et al. 2008; Pirzada et al. 2015; Du et al. 2015). In addition, it exhibits photocatalytic activity only under exposure to UV light (up to approximately $390 \mathrm{~nm}$ ), whereas its ability to absorb light in the visible range is much weaker. Therefore, during recent years, an intensive development of research focused on the improvement and, most importantly, increase of the efficiency of photocatalytic processes involving $\mathrm{TiO}_{2}$ is observed due to the fact that photocatalytic processes conducted under ultraviolet light conditions utilize only a small percentage of available sunlight. The increased activity of titanium dioxide in visible light can be achieved by e.g. modification of its surface. The modification is carried out by addition of transition metal ions (such as $\mathrm{Cr}, \mathrm{Mn}$, Mo) (Michalow et al. 2013; Pouretedal 2018; Park et al. 2013), preparation of the reduced forms of $\mathrm{TiO}_{2-\mathrm{x}}$, sensitization with dyes (Garmaroudi and Mohammadi 2015; Barea and Bisquert 2013), doping with non-metals (such as N, S, C) (Wang et al. 2017; He et al. 2015) and the formation of hybrid materials, such as: $\mathrm{TiO}_{2}-\mathrm{SiO}_{2}, \mathrm{TiO}_{2}-\mathrm{ZrO}_{2}$, $\mathrm{TiO}_{2}-\mathrm{ZnO}$, etc. (Delsouz Khaki et al. 2018; Soltan et al. 2016).

The available literature reports confirm that during recent years much attention has been focused on research aimed at obtaining active titanium dioxide-based photocatalysts characterized by significant oxidative activity. One of them is $\mathrm{TiO}_{2}-\mathrm{SiO}_{2}$ oxide material, made of crystalline titanium dioxide and amorphous silica. The amorphous silica not only improves the mechanical properties of the system but gives products of highly developed surface area. The addition of silica to titania can induce a transformation of anatase form into rutile one, which prevents the growth in size of $\mathrm{TiO}_{2}$ upon thermal treatment. Moreover, silica is responsible for an increase in the surface area of titanium dioxide and stimulates formation of $\equiv \mathrm{Ti}-\mathrm{O}-\mathrm{Si} \equiv$ bonds. Consequently, the photocatalytic activity of $\mathrm{TiO}_{2}-\mathrm{SiO}_{2}$ oxide material increases (Mohamed et al. 2002; Tobaldi et al. 2010; Wu et al. 2009; Messina et al. 2006; Nilchi et al. 2010).

The another way to improve the photocatalytic activity of titanium dioxide is its photosensitizing with dye. Among various organic dyes, chlorophyllin (C), which is a semisynthetic mixture of sodium and copper derivative of chlorophyll, has been widely used as one of the most potential sensitizer of different materials, which are utilized in heterogeneous photocatalysis. This metal porphyrin exhibit high absorption coefficient, fast electron injection speed, slow charge recombination kinetics, and good thermal and chemical stability. Moreover, chlorophyllin is inexpensive, non-toxic, and durable. Many recent studies have focused on utilization of metal porphyrin as a novel sensitizer over different catalytic materials (Gong et al. 2012; Vebber et al. 2016; Joshi et al. 2009; Lüa et al. 2017; Phongamwong et al. 2017; Sun et al. 2013; Krishnakumar et al. 2017). Gong et al. (2012) combined sodium and iron chlorophyllin with $\mathrm{W}$ and $\mathrm{N}$ co-doped $\mathrm{TiO}_{2}$. Authors observed that sodium and iron chlorophyllin sensitized with $\mathrm{W} / \mathrm{N}-\mathrm{TiO}_{2}$ catalyst improves the photoelectrocatalytic activity in the degradation of methyl orange (MO) under visible light irradiation. The charge transfer process under visible light illumination is caused by the electron injection from the excited state of sensitizer molecules to the conduction band of $\mathrm{W} / \mathrm{N}-\mathrm{TiO}_{2}$. Vebber et al. (2016) used sodium and copper chlorophyllin as a visible light sensitizer with combination of poly(allylamine hydrochloride), poly(acrylic acid), and titanium dioxide nanoparticles. Authors evaluated the photocatalytic activity of as-prepared catalysts in the hydrogen production. They demonstred that combination $\mathrm{TiO}_{2}$ with sodium and copper chlorophyllin leads to obtained material which is characterized with better photocatalytic activity in hydrogen production than these components used separately. Moreover, they confirmed that chlorophyllin as an electron donor and copper in $\mathrm{Cu}^{2+}$ form help inhibit the recombination of electron-hole pairs and improve photocatalytic activity of the catalyst. Joshi et al. (2009), immobilized the chlorophyll on different functionalized mesoporous materials. Obtained materials were used as catalysts in the photocatalytic reduction of methyl orange (MO) under the visible light. It was proved that photocatalytic activity of chlorophyll-based 
material indicates that chlorophyll acts as a reaction center, which absorbs visible light and generates electron, which is transferred to different electron acceptors reducing MO. The preparation and comparison of the photocatalytic activity of novel $\mathrm{TiO}_{2} /$ copper porphyrin hybrids were the subject of a report by Lüa et al. (2017). The materials were obtained by impregnation of 5-(4-hydroxy)phenyl-10,15,20-triphenyl copper porphyrin, 5-(4-ethylacetatatomethoxy)-phenyl-10,15,20-triphenyl-copper porphyrin and 5-(4-carboxylato-methoxy)phenyl-10,15,20-triphenyl copper porphyrin onto the surface of different $\mathrm{TiO}_{2}$ samples: commercial $\left(\mathrm{cTiO}_{2}\right)$ and self-prepared $\left(\mathrm{pTiO}_{2}\right)$. It was proved that porphyrins used as dyes to sensitize $\mathrm{TiO}_{2}$, influence the photodegradation processes, improving the photoactivity of $\mathrm{pTiO}_{2}$ more than that of $\mathrm{cTiO}_{2}$. In the case of copper ester porphyrin-sensitized $\mathrm{TiO}_{2}$ photocatalysts, the degradation of 4-nitrophenol was dependent on the properties of the $\mathrm{TiO}_{2}$.

In the present study, we demonstrate for the first time the use of titania-silica hybrid materials conjugated with chlorophyllin as photocatalysts in the decomposition of C.I. Basic Violet 10. It was investigated how the experimental conditions (the initial concentration of chlorophyllin and the contact time of the solution) affect the adsorption efficiency and the physicochemical and photocatalytic properties of the resulting hybrids. Additionally, the kinetics of photooxidation process was investigated using the Langmuir-Hinshelwood equation, assuming the pseudo-first-order reaction (PFO) of pollutant decomposition. The preliminary results are very promising, and provide direct justification of the proposed line of research.

\section{Experimental}

\subsection{Materials}

All chemical reagents used in the experiments, including titanium(IV) isopropoxide (TTIP, 97\%, Sigma-Aldrich), tetraethoxysilane (TEOS, 99\%, Sigma-Aldrich), propan-2-ol (IPA, 99.5\%, Chempur), ammonia $\left(\mathrm{NH}_{3}(\mathrm{aq})\right.$, $25 \%$, Chempur), chlorophyllin sodium copper salt (3-[20-(carboxylatomethyl)-18-(dioxidomethylidene)8-ethenyl-13-ethyl-3,7,12,17-tetramethyl-2,3-dihydroporphyrin-22-id-2-yl]propanoate copper complex sodium salt, Sigma-Aldrich) and C.I. Basic Violet 10 (Rhodamine BRB, 95\%, Sigma-Aldrich), were used without any further purification.

\subsection{Synthesis of $\mathrm{TiO}_{2}-\mathrm{SiO}_{2}$ support}

A synthetic inorganic $\mathrm{TiO}_{2}-\mathrm{SiO}_{2}$ oxide system (sample TS) was prepared by the sol-gel route. Synthesis of the titania-silica material was carried out in a laboratory reactor of LR-2.
ST type (Ika Werke $\mathrm{GmbH}$ ) with $2 \mathrm{dm}^{3}$ capacity, equipped with a heating jacket and high-speed anchor stirrer operating at $300 \mathrm{rpm}$. Firstly, $0.58 \mathrm{~mol}$ of an organic precursor of $\mathrm{TiO}_{2}$ (titanium(IV) isopropoxide) was dissolved in $13.08 \mathrm{~mol}$ of propan-2-ol, at room temperature. Then $0.50 \mathrm{~mol}$ of an organic precursor of $\mathrm{SiO}_{2}$ (tetraethoxysilane) was introduced into the reactor, at a constant rate of $6 \mathrm{~cm}^{3} / \mathrm{min}$, using an ISM833A peristaltic pump (ISMATEC). The reaction mixture was additionally stirred for $10 \mathrm{~min}$, and after that time the promoter of hydrolysis — ammonia (3.93 mol) — was added using a peristaltic pump at a constant rate of $6 \mathrm{~cm}^{3} / \mathrm{min}$. The synthesized colloidal suspension was stirred for $1 \mathrm{~h}$. The obtained alcogel was then placed in an SEL-I3 chamber drier (Memmert $\mathrm{GmbH}$ ) operating at $105^{\circ} \mathrm{C}$ for $24 \mathrm{~h}$. Next, to remove impurities, the resulting white precipitate was washed several times with deionized water. This was followed by filtration of the mixture under reduced pressure. Finally, the washed powder was dried by convection at $105^{\circ} \mathrm{C}$ for $6 \mathrm{~h}$ and then calcined at $600{ }^{\circ} \mathrm{C}$ for $2 \mathrm{~h}$, with heating rate $5^{\circ} \mathrm{C} / \mathrm{min}$ (using a Nabertherm P320 Controller). A schematic diagram of the synthesis of the titania-silica support appears in Fig. 1.

\subsection{Adsorption and desorption of chlorophyllin on $\mathrm{TiO}_{2}-\mathrm{SiO}_{2}$ oxide material}

Adsorption experiments were performed using a reactor containing $1.0 \mathrm{~g}$ of $\mathrm{TiO}_{2}-\mathrm{SiO}_{2}$ oxide material as adsorbent, and $50 \mathrm{~cm}^{3}$ of aqueous solution of chlorophyllin (sample C) in appropriate concentration (water solutions of the sensitizer were prepared with concentrations of 25,50 and $100 \mathrm{mg} /$ $\mathrm{dm}^{3}$ ). The obtained suspension was stirred for a maximum of 180 min with an IKAMAG R05 magnetic stirrer (IKA Werke $\mathrm{GmbH}$ ). After different time intervals (1 min-TSC1, TSC11 and TSC21, $3 \mathrm{~min}$-TSC2, TSC12 and TSC22, $5 \mathrm{~min}-\mathrm{TSC} 3$, TSC13 and TSC23, $10 \mathrm{~min}-\mathrm{TSC} 4, \mathrm{TSC} 14$ and TSC24, $15 \mathrm{~min}$-TSC5, TSC15 and TSC25, $30 \mathrm{~min}$-TSC6, TSC16 and TSC26, $60 \mathrm{~min}-\mathrm{TSC} 7, \mathrm{TSC} 17$ and TSC27, $90 \mathrm{~min}-$ TSC8, TSC18 and TSC28, $120 \mathrm{~min}$ - TSC9, TSC19 and TSC29 and $180 \mathrm{~min}-\mathrm{TSC} 10$, TSC20 and TSC30) samples (obtained by adsorption of chlorophyllin in an initial concentrations of 25,50 and $100 \mathrm{mg} / \mathrm{dm}^{3}$, respectively) were filtered off under reduced pressure, and the obtained filtrates were analyzed using a UV-Vis spectrophotometer (V-750, Jasco) at maximum absorbance wavelength $405 \mathrm{~nm}$. The concentration of the adsorbed chlorophyllin was read off from the calibration curve $(y=0.0459 x)$. The efficiency of chlorophyllin adsorption on the $\mathrm{TiO}_{2}-\mathrm{SiO}_{2}$ oxide system $(E)$ was determined using the formula:

$$
E(\%)=\left(1-\frac{c_{t c}}{c_{0 c}}\right) \cdot 100 \%
$$




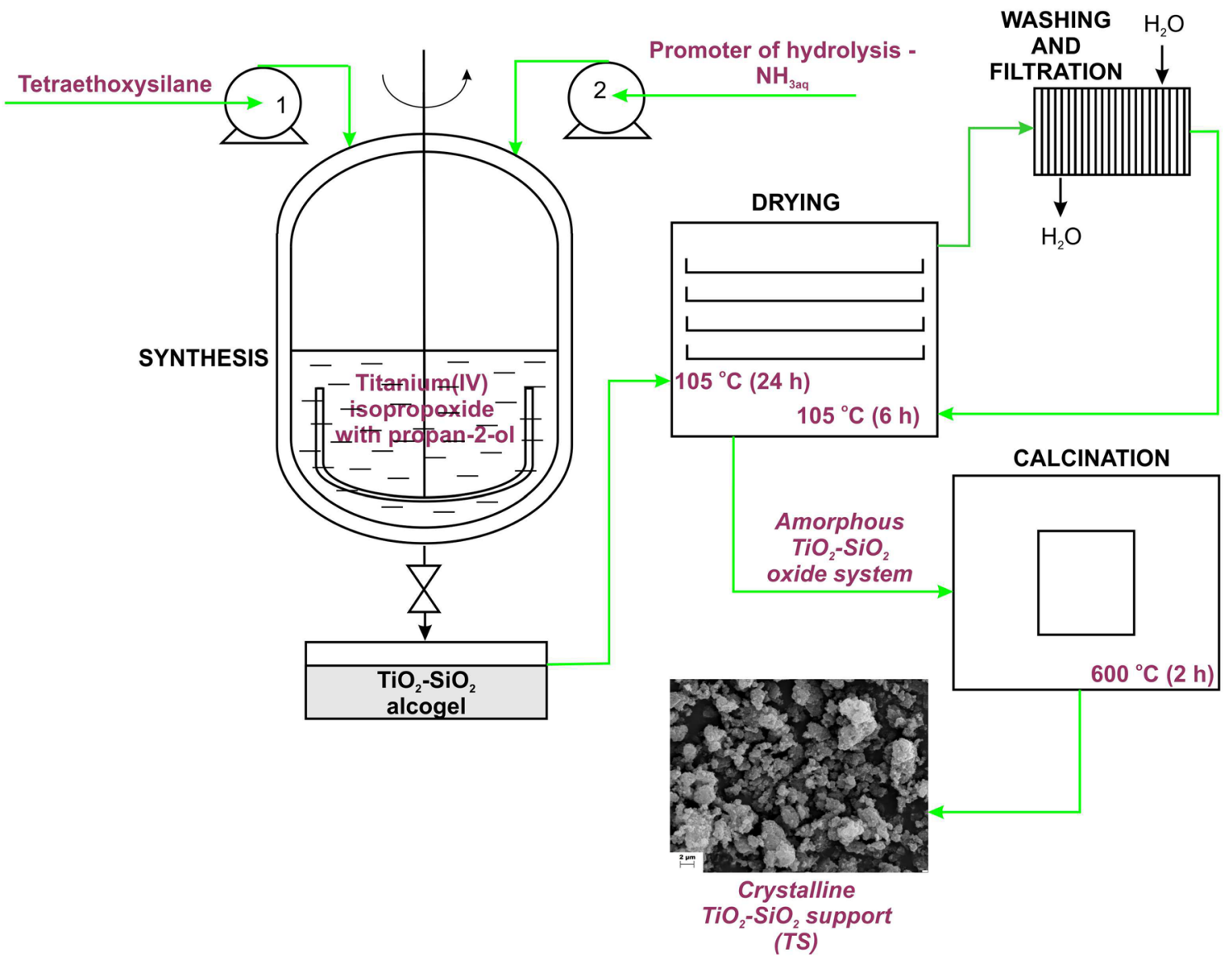

Fig. 1 Route of synthesis of titania-silica support

where $c_{0 c}$ and $c_{t c}$ are the concentrations of chlorophyllin before and after adsorption, respectively $\left(\mathrm{mg} / \mathrm{dm}^{3}\right)$. The resulting sediment was dried in a stationary drier for $24 \mathrm{~h}$ at $105^{\circ} \mathrm{C}$.

The next stage of the study involved an evaluation of the stability of the $\mathrm{TiO}_{2}-\mathrm{SiO}_{2}$ /chlorophyllin hybrids (samples TSC) in desorption tests. To a conical flask containing $100 \mathrm{~cm}^{3}$ water, a portion of $0.5 \mathrm{~g}$ of the selected materials (after adsorption times of 30 and $180 \mathrm{~min}$ ) was added. The resulting suspension was mixed with an IKAMAG R05 magnetic stirrer (IKA Werke $\mathrm{GmbH}$ ) at room temperature for $1 \mathrm{~h}$. After this time the reaction mixture was filtered off under reduced pressure, and the concentration of the eluted chlorophyllin in the filtrate was evaluated (absorbance measurements on the V-750 spectrophotometer). The concentration of the eluted chlorophyllin was read off from the calibration curve $(y=0.0459 x)$. The amount of chlorophyllin eluted $(X)$ from the surface of the titania-silica support was calculated using the formula:

$X(\%)=100-\frac{\left[\left(c_{0 c}-c_{t c}\right)-4 \cdot c_{w c}\right] \cdot 100}{\left(c_{0 c}-c_{t c}\right)}$ where $c_{0 c}$ and $c_{t c}$ are the concentrations of chlorophyllin before and after adsorption $\left(\mathrm{mg} / \mathrm{dm}^{3}\right)$ and $c_{w c}$ is the concentration of the chlorophyllin eluted from the support $\left(\mathrm{mg} / \mathrm{dm}^{3}\right)$.

\subsection{Determination of physicochemical properties}

To determine the physicochemical and structural properties of the obtained titania-silica oxide system and $\mathrm{TiO}_{2}-\mathrm{SiO}_{2} /$ chlorophyllin hybrids, comprehensive analysis was carried out using the most advanced analytical methods and techniques.

The particle size distribution (PSD) and polydispersity index (PdI) of the $\mathrm{TiO}_{2}-\mathrm{SiO}_{2}$ sample was measured using a Zetasizer Nano ZS (Malvern Instruments Ltd.), enabling measurements in the range $0.6-6000 \mathrm{~nm}$ by the non-invasive back-scatter method (NIBS). The sample was prepared by dispersing $0.01 \mathrm{~g}$ of the tested product in $25 \mathrm{~cm}^{3}$ of propan2-ol. The system was stabilized in an ultrasonic bath for $15 \mathrm{~min}$, and was then placed in a cuvette and analyzed.

The surface morphology and microstructure of the $\mathrm{TiO}_{2}-\mathrm{SiO}_{2}$ material were examined on the basis of SEM images recorded from an EVO40 scanning electron 
microscope (Zeiss). Before testing, the sample was coated with Au for $5 \mathrm{~s}$ using a Balzers PV205P coater.

Porous structure parameters (BET surface area, pore volume and pore diameter) were determined using an ASAP 2020 physisorption analyzer (Micromeritics Instrument Co.) by the Brunauer-Emmett-Teller (BET) method based on low-temperature $\mathrm{N}_{2}$ sorption. All powders were degassed at $120{ }^{\circ} \mathrm{C}$ for $4 \mathrm{~h}$ before measurement. The surface area was determined by the multipoint BET method using adsorption data in a relative pressure $\left(p / p_{0}\right)$ range of $0.06-0.30$ (Kruk and Jaroniec 2001). The adsorption isotherm was used to determine the pore size distribution by the Barrett-Joyner-Halenda (BJH) method using the Halsey equation as well as the total volume of pores.

$\mathrm{X}$-ray diffraction (XRD) pattern of titania-silica material was used to determine the identity of any phases present. The XRD analysis was performed on a TUR-M62 diffractometer using $\mathrm{Cu} \mathrm{K} \alpha$ radiation ( $\alpha=1.5418 \AA$ ), Ni-filtered. The accelerating voltage and applied current were $30 \mathrm{kV}$ and $25 \mathrm{~mA}$. The X-ray diffraction pattern data were collected in step-scanning mode with steps of $\Delta 2 \theta=0.04^{\circ}$, over an angular range of $10-60^{\circ}$.

The chemical characterization of samples was analyzed by energy dispersive X-ray spectroscopy (EDS) using a Princeton Gamma-Tech unit equipped with a prism digital spectrometer. The EDS technique is based on analysis of $\mathrm{X}$-ray energy values using a semiconductor. Representative parts $\left(500 \mu \mathrm{m}^{2}\right)$ were analyzed to determine their actual surface composition.

The chemical composition of $\mathrm{TiO}_{2}-\mathrm{SiO}_{2}$ and randomly selected $\mathrm{TiO}_{2}-\mathrm{SiO}_{2} /$ chlorophyllin hybrids was determined using a Vario EL Cube apparatus (Elementar Analysensysteme $\mathrm{GmbH}$ ). The results of BET and elemental analysis (EA) were used to calculate the degree of coverage of the $\mathrm{TiO}_{2}-\mathrm{SiO}_{2}$ sample with chlorophyllin from the Berendsen and de Golan equation (Berendsen and de Golan 1978).

The efficiency of adsorption on the surface of the $\mathrm{TiO}_{2}-\mathrm{SiO}_{2}$ material was confirmed by Fourier transform infrared spectroscopy (FTIR) measurements, performed using a Vertex 70 spectrophotometer (Bruker). The selected materials were analyzed in the form of tablets, made by pressing a mixture of anhydrous $\mathrm{KBr}(\mathrm{ca} .0 .25 \mathrm{~g}$ ) and $1 \mathrm{mg}$ of the tested substance in a special steel ring under a pressure of approximately $10 \mathrm{MPa}$.

A thermogravimetric analyzer (Jupiter STA 449F3, Netzsch) was used to investigate the thermal stability of the samples. Measurements were carried out under nitrogen flow $\left(20 \mathrm{~cm}^{3} / \mathrm{min}\right)$ at a heating rate of $10{ }^{\circ} \mathrm{C} / \mathrm{min}$ over a temperature range of $30-1000{ }^{\circ} \mathrm{C}$, with an initial sample weight of approximately $5 \mathrm{mg}$.

\subsection{Kinetic study of adsorption}

The quantity of chlorophyllin retained by the $\mathrm{TiO}_{2}-\mathrm{SiO}_{2}$ support at time $t$ was calculated using the following equation:

$q_{t}=\frac{\left(c_{0 c}-c_{t c}\right) \cdot V}{m}$

where $c_{0 c}$ and $c_{t c}$ are the concentrations of chlorophyllin before and after adsorption $\left(\mathrm{mg} / \mathrm{dm}^{3}\right), V$ is the volume of solution $\left(\mathrm{dm}^{3}\right)$ and $m$ is the mass of $\mathrm{TiO}_{2}-\mathrm{SiO}_{2}(\mathrm{~g})$.

Kinetic adsorption data were modelled using both pseudo-first-order (PFO) and pseudo-second-order (PSO) kinetic equations, as follows (Lagergren 1898; Ho and McKay 1999):

- pseudo-first-order (Lagergren equation):

$$
\log \left(q_{e}-q_{t}\right)=\log q_{e}-\frac{k_{1}}{2.303} \cdot t
$$

- pseudo-second-order (Ho and McKay equation):

$$
\frac{t}{q_{t}}=\frac{1}{k_{2} \cdot q_{e}^{2}}+\frac{1}{q_{e}} \cdot t
$$

where $q_{e}$ and $q_{t}(\mathrm{mg} / \mathrm{g})$ are the quantities of chlorophyllin adsorbed by $\mathrm{TiO}_{2}-\mathrm{SiO}_{2}$ material at equilibrium and time $t$ respectively, $k_{l}(1 / \mathrm{min})$ is the rate constant of the pseudo-first-order kinetic model, and $k_{2}(\mathrm{~g} / \mathrm{mg} \mathrm{min})$ is the rate constant of the pseudo-second-order kinetic model.

The equilibrium adsorption capacity $\left(q_{e}\right)$ and adsorption rate constants $\left(k_{1}\right.$ and $\left.k_{2}\right)$ were calculated using experimentally obtained plots of $\log \left(q_{e}-q_{t}\right)$ versus $t$ and $t / q t$ versus $t$.

\subsection{Evaluation of photocatalytic activity}

The photocatalytic activity of selected samples was evaluated based on the degradation of a model water solution of C.I. Basic Violet 10 (RB). The photocatalytic test was carried out in a UV-RS2 laboratory reactor (Heraeus) with a $150 \mathrm{~W}$ medium-pressure mercury lamp as a UV light source, surrounded by a water-cooling quartz jacket. Firstly, an appropriate amount of photocatalyst $(4 \mathrm{mg})$ was added to $100 \mathrm{~cm}^{3}$ of the model organic impurity, in an initial concentration of $5 \mathrm{mg} / \mathrm{dm}^{3}$. Before UV irradiation, the obtained suspension was magnetically stirred for $30 \mathrm{~min}$ to ensure that the adsorption/desorption equilibrium of the reaction solution was attained. After that time the radiation was turned on to initiate the photocatalytic reaction. In the next step, the irradiated mixtures were collected from the reactor at regular intervals $(5,10,20,30,45,60,90,120,150,180 \mathrm{~min})$ and 
centrifuged to separate the photocatalyst. The concentration of organic dye (after adsorption and UV irradiation) was analyzed using a UV-Vis spectrophotometer (V-750, Jasco), at a wavelength of $553 \mathrm{~nm}$, using water as a reference. The concentration of the adsorbed or degraded C.I. Basic Violet 10 was read off from the calibration curve $(y=0.22 x)$. The photocatalytic activity of the samples was determined by calculating the yield of organic impurity degradation $(W)$, using the formula:

$W(\%)=\left(1-\frac{c_{t R B}}{c_{0 R B}}\right) \cdot 100 \%$

where $c_{O R B}$ and $c_{t R B}$ are the concentrations of C.I. Basic Violet 10 before and after irradiation $\left(\mathrm{mg} / \mathrm{dm}^{3}\right)$.

\subsection{Kinetic study of photocatalysis}

The researches evaluated the degree of removal of the selected organic pollutant from aqueous solutions in heterogeneous photocatalysis. The kinetics of performed process is based on the analysis of the change in the concentration of the analyzed compound as a function of the irradiation time of the reaction mixtures. This allows determining rate constants of the decomposition reactions and the half-life time of pollutant.

Kinetic of the photocatalytic degradation of C.I. Basic Violet 10 was described by determining the rate constant from the Langmuir-Hinshelwood equation, as a dependence of the dye concentration in the tested aqueous solutions under investigation since the UV irradiation (Eq. 7):

$r=\frac{d c_{R B}}{d t}=k\left(\frac{K c_{R B}}{1+K c_{R B}}\right)$

Assuming that the decomposition of C.I. Basic Violet 10 in the photocatalysis process is of pseudo-first-order reaction, the constant reaction rate can be determined as the slope of the linear regression (Eq. 8):

$-\ln \left(\frac{c_{t R B}}{c_{0 R B}}\right)=k t$

where $k$ is the rate of degradation rate of C.I. Basic Violet $10, \mathrm{~min}^{-1}, K$ is the equilibrium constant of adsorption of C.I. Basic Violet 10 on the surface of the catalyst; $c_{O R B}, c_{t R B}$ is the concentrations of C.I. Basic Violet 10 in aqueous solution before irradiation $(\mathrm{t}=0)$ and after define time $t$.

Knowledge of the constant reaction rate $k$ allows to determine the half-life time of the model organic pollutant on the basis of Eq. (9):

$t_{\frac{1}{2}}=\frac{\ln 2}{k}$

\section{Results and discussion}

\subsection{Properties of the support}

The first stage of the study concerned the properties of the $\mathrm{TiO}_{2}-\mathrm{SiO}_{2}$ oxide system (sample TS), which was used as a support for chlorophyllin in the adsorption process. The obtained results is described in detail in Supplementary Material (see Fig. S1).

\subsection{Adsorption efficiency and stability of $\mathrm{TiO}_{2}-\mathrm{SiO}_{2} /$ chlorophyllin hybrids}

The main aim of the study was to evaluate the efficiency of chlorophyllin adsorption on the surface of the inorganic $\mathrm{TiO}_{2}-\mathrm{SiO}_{2}$ support, and the stability of the resulting hybrids (see Tables 1,2).
Table 1 Adsorption efficiency (E) of chlorophyllin on the $\mathrm{TiO}_{2}-\mathrm{SiO}_{2}$ material

\begin{tabular}{|c|c|c|c|c|c|c|}
\hline \multirow{3}{*}{$\begin{array}{l}\text { Adsorption time } \\
\text { (min) }\end{array}$} & \multicolumn{6}{|c|}{ Initial concentration of chlorophyllin $\left(\mathrm{mg} / \mathrm{dm}^{3}\right)$} \\
\hline & $\begin{array}{l}\text { Acronym of } \\
\text { sample }\end{array}$ & 25 & $\begin{array}{l}\text { Acronym of } \\
\text { sample }\end{array}$ & 50 & $\begin{array}{l}\text { Acronym of } \\
\text { sample }\end{array}$ & 100 \\
\hline & $E(\%)$ & & & & & \\
\hline 1 & TSC1 & 93.6 & TSC11 & 98.8 & TSC21 & 96.4 \\
\hline 3 & TSC2 & 93.4 & TSC12 & 91.5 & $\mathrm{TSC} 22$ & 96.0 \\
\hline 5 & TSC3 & 96.5 & TSC13 & 97.7 & $\mathrm{TSC} 23$ & 97.1 \\
\hline 10 & TSC4 & 95.6 & TSC14 & 96.7 & TSC24 & 95.8 \\
\hline 15 & TSC5 & 96.5 & TSC15 & 96.5 & TSC25 & 87.8 \\
\hline 30 & TSC6 & 97.1 & TSC16 & 88.9 & TSC26 & 94.8 \\
\hline 60 & TSC7 & 97.4 & TSC17 & 90.7 & TSC27 & 96.1 \\
\hline 90 & TSC8 & 96.6 & TSC18 & 92.3 & TSC 28 & 90.0 \\
\hline 120 & TSC9 & 97.0 & TSC19 & 96.6 & TSC29 & 97.2 \\
\hline 180 & TSC10 & 98.1 & TSC20 & 97.5 & TSC30 & 93.0 \\
\hline
\end{tabular}


Table 2 Degree of elution of chlorophyllin $(X)$ from the $\mathrm{TiO}_{2}-\mathrm{SiO}_{2}$ support

\begin{tabular}{llrllll}
\hline $\begin{array}{l}\text { Adsorption } \\
\text { time }(\mathrm{min})\end{array}$ & \multicolumn{5}{l}{ Initial concentration of chlorophyllin $\left(\mathrm{mg} / \mathrm{dm}^{3}\right)$} \\
\cline { 2 - 7 } & Acronym of sample & 25 & Acronym of sample & 50 & Acronym of sample & 100 \\
& $X(\%)$ & 10.8 & TSC16D & 7.6 & TSC26D & 2.9 \\
30 & TSC6D & 7.8 & TSC20D & 2.5 & TSC30D & 2.4 \\
\hline
\end{tabular}

Table 1 presents the efficiencies of adsorption of chlorophyllin on the synthetic $\mathrm{TiO}_{2}-\mathrm{SiO}_{2}$ support surface. Adsorption of chlorophyllin was performed using concentrations of 25,50 and $100 \mathrm{mg} / \mathrm{dm}^{3}$.

The results showed that in the first period of the process chlorophyllin is strongly adsorbed on the surface of the synthetic $\mathrm{TiO}_{2}-\mathrm{SiO}_{2}$ support independently of its initial concentration. Independent of the initial concentration of chlorophyllin, its adsorption efficiency is over $90 \%$ in most cases. The high efficiency of adsorption may result from the high affinity of functional groups (especially due to the three carboxylate groups) occurring in the structure of the chlorophyllin to functional groups present on the inorganic $\mathrm{TiO}_{2}-\mathrm{SiO}_{2}$ material. The highest adsorption efficiency was obtained for samples TSC10 (98.1\%, initial concentration $25 \mathrm{mg} / \mathrm{dm}^{3}$, adsorption time-180 min), TSC11 (98.8\%, initial concentration $50 \mathrm{mg} / \mathrm{dm}^{3}$, adsorption time-1 $\mathrm{min}$ ) and TSC29 (97.2\%, initial concentration $100 \mathrm{mg} / \mathrm{dm}^{3}$, adsorption time-120 min). Moreover, for the obtained hybrids, independently of the initial concentration of chlorophyllin used and the duration of the adsorption process, the efficiency of adsorption is maintained constantly high. Our observations are in agreement with Norman et al. (2016), who also observed the high efficiency of chlorophyllin adsorption on the natural biopolymer $H$. communis.

The data in Table 2, describing the stability of the $\mathrm{TiO}_{2}-\mathrm{SiO}_{2} /$ chlorophyllin hybrids, show that the degree of elution of chlorophyllin decreases with increasing chlorophyllin concentration in the initial solution. Moreover, the degree of elution from the $\mathrm{TiO}_{2}-\mathrm{SiO}_{2}$ support is greater for chlorophyllin adsorbed from a solution with concentration $25 \mathrm{mg} / \mathrm{dm}^{3}$ : in this case the degree of elution from the inorganic material is $10.8 \%$ for the sample obtained by adsorption over $30 \mathrm{~min}$ (sample TSC6D), and $7.8 \%$ for the sample obtained by adsorption over $180 \mathrm{~min}$ (sample TSC10D). The hybrids obtained by adsorption of chlorophyllin from a solution with concentration $100 \mathrm{mg} / \mathrm{dm}^{3}-$ samples TSC26D and TSC30D, were much more durable (see Table 2).

The degree of elution of chlorophyllin from the $\mathrm{TiO}_{2}-\mathrm{SiO}_{2}$ surface was somewhat unpredictable. In general, the degree of elution was rather low, but the highest value of about $10.8 \%$ was recorded for the hybrid obtained by adsorption of chlorophyllin over $30 \mathrm{~min}$ from an initial solution of concentration $25 \mathrm{mg} / \mathrm{dm}^{3}$ (sample TSC6D). The lowest degree of dye elution $(2.4 \%)$ was recorded for the hybrid obtained by adsorption of chlorophyllin over $180 \mathrm{~min}$ from an initial solution of concentration $100 \mathrm{mg} / \mathrm{dm}^{3}$ (sample TSC30D).

In conclusion, the chlorophyllin was effectively adsorbed on the surface of the $\mathrm{TiO}_{2}-\mathrm{SiO}_{2}$ support. Moreover, the degree of elution of chlorophyllin from the surface of the $\mathrm{TiO}_{2}-\mathrm{SiO}_{2}$ material was lower, which means that the former hybrids are more stable. However, Norman et al. (2016) did not observe desorption of chlorophyllin from the surface of the natural biopolymer $H$. communis, this being attributed to the chemical bonding of chlorophyllin to the spongin-based sponge skeletons.

Based on the obtained efficiencies of adsorption and degrees of elution, it was proved that chlorophyllin has a strong affinity to the $\mathrm{TiO}_{2}-\mathrm{SiO}_{2}$ material. The interactions are relatively strong, as is confirmed by the low percentages of elution of chlorophyllin from the inorganic support.
Table 3 Parameters of the porous structure of $\mathrm{TiO}_{2}-\mathrm{SiO}_{2} /$ chlorophyllin hybrids

\begin{tabular}{llllll}
\hline $\begin{array}{l}\text { Acronym of } \\
\text { sample }\end{array}$ & $\begin{array}{l}\text { Initial concentration of } \\
\text { chlorophyllin }\left(\mathrm{mg} / \mathrm{dm}^{3}\right)\end{array}$ & $\begin{array}{l}\text { Adsorption } \\
\text { time }(\mathrm{min})\end{array}$ & $\begin{array}{l}\text { Surface area } \\
\mathrm{A}_{\mathrm{BET}}\left(\mathrm{m}^{2} / \mathrm{g}\right)\end{array}$ & $\begin{array}{l}\text { Total pore vol- } \\
\text { ume } \mathrm{V}_{\mathrm{p}}\left(\mathrm{cm}^{3} / \mathrm{g}\right)\end{array}$ & $\begin{array}{l}\text { Average pore } \\
\text { size } \mathrm{S}_{\mathrm{p}}(\mathrm{nm})\end{array}$ \\
\hline $\mathrm{TS}$ & - & - & 282 & 0.169 & 2.8 \\
TSC6 & 25 & 1 & 267 & 0.112 & 3.2 \\
TSC10 & & 180 & 266 & 0.114 & 3.2 \\
TSC16 & 50 & 1 & 265 & 0.113 & 3.2 \\
TSC20 & & 180 & 265 & 0.115 & 3.1 \\
TSC26 & 100 & 1 & 264 & 0.115 & 3.1 \\
TSC30 & & 180 & 263 & 0.116 & 3.1 \\
\hline
\end{tabular}




\subsection{Parameters of the porous structure}

The textural characteristics of the obtained materials were assessed from nitrogen adsorption/desorption isotherms at $-196{ }^{\circ} \mathrm{C}$. The results are summarized in Table 3 .

The surface areas of the $\mathrm{TiO}_{2}-\mathrm{SiO}_{2} /$ chlorophyllin samples are slightly lower than that of pure $\mathrm{TiO}_{2}-\mathrm{SiO}_{2}$. This is probably related to the blocking of active centers of the titania-silica support by chlorophyllin molecules. As Table 3 shows, the $\mathrm{A}_{\mathrm{BET}}$ surface area of the $\mathrm{TiO}_{2}-\mathrm{SiO}_{2}$ /chlorophyllin hybrids slightly decreases with increasing initial concentration of chlorophyllin used for the adsorption process. Exemplary adsorption/desorption isotherms of the TSC10 and TSC30 hybrids are shown in Fig. S2.

\subsection{Degree of coverage of inorganic support by chlorophyllin}

At the next stage, the effectiveness of adsorption of chlorophyllin on the surface of the $\mathrm{TiO}_{2}-\mathrm{SiO}_{2}$ support was evaluated based on the increase in the percentage content of characteristic elements in the hybrid materials, compared with their content in the pure $\mathrm{TiO}_{2}-\mathrm{SiO}_{2}$ sample. The degrees of coverage of $\mathrm{TiO}_{2}-\mathrm{SiO}_{2}$ with chlorophyllin were calculated from the results of EA using the Berendsen and de Golan equation (Berendsen and de Golan 1978) (Table 4). The highest percentage content of carbon $(0.632 \%)$ and nitrogen $(0.163 \%)$ was recorded in the hybrid obtained by adsorption of chlorophyllin from a solution of concentration $100 \mathrm{mg} /$ $\mathrm{dm}^{3}$ over 30 min (sample TSC26). Hybrids obtained using chlorophyllin in an initial concentration of $50 \mathrm{mg} / \mathrm{dm}^{3}$ (samples TSC11, TSC16 and TSC20) had carbon and nitrogen contents in the ranges $0.308-0.356 \%$ and $0.115-0.136 \%$ respectively. The contents of carbon and nitrogen in the TSC hybrids (samples TSC1, TSC6 and TSC10) obtained by adsorption of chlorophyllin in an initial concentration of $25 \mathrm{mg} / \mathrm{dm}^{3}$ were in the ranges $0.199-0.288 \% \mathrm{C}$ and $0.101-0.122 \% \mathrm{~N}$. For all of the obtained hybrids, the degree of $\mathrm{TiO}_{2}-\mathrm{SiO}_{2}$ surface coverage was found to be in the range $0.017-0.056 \mu \mathrm{mol} / \mathrm{m}^{2}$. The results of EA provide direct evidence of the effectiveness of the adsorption process. Moreover, with increasing concentration of chlorophyllin used for adsorption, there was an increase in the elemental contents of nitrogen, carbon and hydrogen, along with a significant increase in the degree of coverage. The highest degrees of coverage were obtained for samples obtained by adsorption of chlorophyllin from a solution with a concentration of $100 \mathrm{mg} / \mathrm{dm}^{3}$ (samples TSC21, TSC26 and TSC30).

The effectiveness of adsorption for the $\mathrm{TiO}_{2}-\mathrm{SiO}_{2} /$ chlorophyllin hybrids was also verified on the basis of energy dispersive X-ray microanalysis (EDS) (Table 5). The main purpose of EDS analysis was to confirm the presence of titanium, silicon, oxygen, copper and sodium, which ought to be present in the synthetic $\mathrm{TiO}_{2}-\mathrm{SiO}_{2}$ material and the chlorophyllin used in the adsorption process. Analysis of the composition of samples TSC 10 , TSC 20 and TSC 30 showed that they contain respectively $40.5 \%, 40.2 \%$ and $39.4 \% \mathrm{Ti}$; $19.2 \%, 19.1 \%$ and $19.0 \% \mathrm{Si} ; 40.1 \%, 40.4 \%$ and $41.3 \% \mathrm{O}$;
Table 4 Degree of surface coverage of $\mathrm{TiO}_{2}-\mathrm{SiO}_{2}$ with chlorophyllin

Table 5 Chemical composition of $\mathrm{TiO}_{2}-\mathrm{SiO}_{2}$ material after adsorption of chlorophyllin

\begin{tabular}{lllllll}
\hline $\begin{array}{llllll}\text { Acronym of } \\
\text { sample }\end{array}$ & $\begin{array}{l}\text { Initial concentration of } \\
\text { chlorophyllin }\left(\mathrm{mg} / \mathrm{dm}^{3}\right)\end{array}$ & $\begin{array}{l}\text { Adsorption } \\
\text { time }(\mathrm{min})\end{array}$ & \multicolumn{2}{l}{ Elemental analysis $(\%)$} & $\mathrm{P}\left(\mu \mathrm{mol} / \mathrm{m}^{2}\right)$ \\
\cline { 5 - 6 } & & & $\mathrm{N}$ & $\mathrm{C}$ & $\mathrm{H}$ & \\
\hline TS & - & 1 & 0.091 & 0.098 & 1.099 & - \\
TSC1 & 25 & 30 & 0.122 & 0.199 & 1.121 & 0.017 \\
TSC6 & & 180 & 0.101 & 0.201 & 1.204 & 0.019 \\
TSC10 & & 1 & 0.113 & 0.288 & 1.180 & 0.025 \\
TSC11 & 50 & 30 & 0.136 & 0.327 & 1.118 & 0.029 \\
TSC16 & & 180 & 0.115 & 0.308 & 1.267 & 0.027 \\
TSC20 & & 1 & 0.127 & 0.356 & 1.167 & 0.031 \\
TSC21 & 100 & 30 & 0.132 & 0.544 & 1.115 & 0.048 \\
TSC26 & & 180 & 0.163 & 0.632 & 1.178 & 0.056 \\
TSC30 & & 0.109 & 0.488 & 1.168 & 0.043 \\
\hline
\end{tabular}

\begin{tabular}{|c|c|c|c|c|c|c|c|}
\hline \multirow{2}{*}{$\begin{array}{l}\text { Acronym of } \\
\text { sample }\end{array}$} & \multirow{2}{*}{$\begin{array}{l}\text { Initial concentration of } \\
\text { chlorophyllin }\left(\mathrm{mg} / \mathrm{dm}^{3}\right)\end{array}$} & \multirow{2}{*}{$\begin{array}{l}\text { Adsorption } \\
\text { time (min) }\end{array}$} & \multicolumn{5}{|c|}{ Mass contribution (\%) } \\
\hline & & & $\mathrm{Ti}$ & $\mathrm{Si}$ & $\mathrm{O}$ & $\mathrm{Cu}$ & $\mathrm{Na}$ \\
\hline TS & - & - & 41.3 & 19.3 & 39.4 & - & - \\
\hline TSC10 & 25 & 180 & 40.5 & 19.2 & 40.1 & 0.1 & 0.1 \\
\hline TSC20 & 50 & 180 & 40.2 & 19.1 & 40.4 & 0.2 & 0.1 \\
\hline TSC30 & 100 & 180 & 39.4 & 19.0 & 41.3 & 0.2 & 0.1 \\
\hline
\end{tabular}


$0.1 \%, 0.2 \%$ and $0.2 \% \mathrm{Cu}$; and $0.1 \% \mathrm{Na}$. EDS analysis of the TSC hybrids shows that with increasing initial concentration of chlorophyllin there is an increase in the mass contribution of $\mathrm{Cu}$ (a characteristic element of chlorophyllin). Norman et al. (2016) also used energy dispersive X-ray microanalysis to confirm the efficiency of adsorption of chlorophyllin on $H$. communis, and observed the presence of characteristic elements from both chlorophyllin and the sponge material in the obtained hybrids.

\subsection{FTIR spectra of obtained materials}

To confirm the effectiveness of adsorption, FTIR spectra were obtained for the chlorophyllin, the $\mathrm{TiO}_{2}-\mathrm{SiO}_{2}$ material and selected TSC hybrids (Fig. 2).

The FTIR spectrum of chlorophyllin shows a broad signal in the range $3650-3350 \mathrm{~cm}^{-1}$, attributed to stretching vibrations of $\mathrm{O}-\mathrm{H}$ and $\mathrm{N}-\mathrm{H}$ groups. Moreover, two bands with significant intensity with maxima at wavenumbers of 2929 and $2859 \mathrm{~cm}^{-1}$ are characteristic for $\mathrm{C}-\mathrm{H}$ stretching vibrations. The spectrum of chlorophyllin also contains bands for stretching vibrations of the carboxylate anion $(\mathrm{C}=\mathrm{O})$ at $1632 \mathrm{~cm}^{-1}$, and skeletal vibrations of the porphyrin ring formed by $\mathrm{C}=\mathrm{C}$ and $\mathrm{C}=\mathrm{N}$ bonds at $1565 \mathrm{~cm}^{-1}$. There are also absorption bands at 1404 and $1107 \mathrm{~cm}^{-1}$ attributed to $\mathrm{C}-\mathrm{O}$ stretching vibrations, and a band at $1276 \mathrm{~cm}^{-1}$ attributed to $\mathrm{C}-\mathrm{N}$ stretching vibrations. There are also clear signals at 1220 and $1074 \mathrm{~cm}^{-1}$, originating from stretching vibrations of $\mathrm{C}-\mathrm{O}-\mathrm{C}$ ester bonds. The three characteristic absorption bands at 991,959 and $924 \mathrm{~cm}^{-1}$ correspond to $\mathrm{C}-\mathrm{C}$ stretching and bending vibrations in the pyrrole ring. The copper present in the structure of the chlorophyllin was observed in the range $750-570 \mathrm{~cm}^{-1}$ (Norman et al. 2016; Phongamwong et al. 2017).

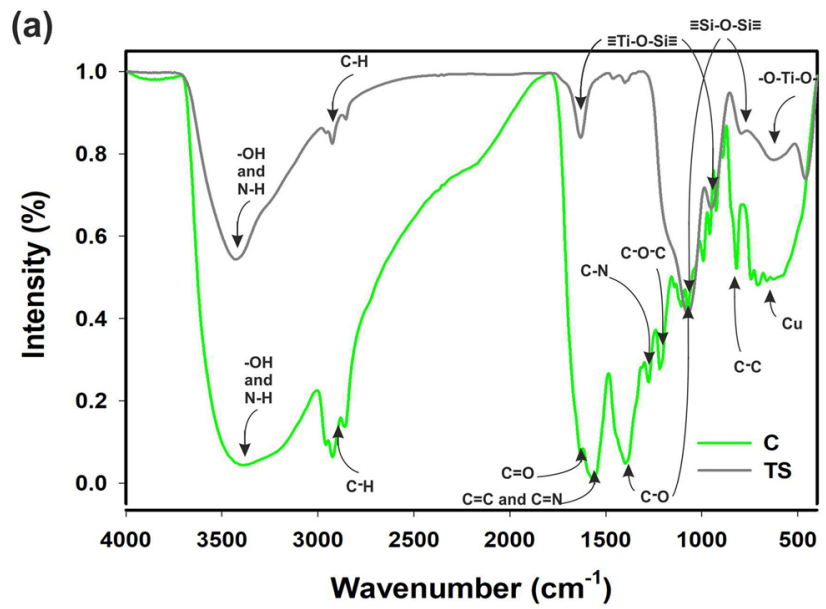

The FTIR spectrum of the $\mathrm{TiO}_{2}-\mathrm{SiO}_{2}$ support contains an absorption band at $678 \mathrm{~cm}^{-1}$, attributed to symmetric -O-Ti-O- stretching vibrations. The vibration of $\equiv$ Ti-O- bonds was observed at $505 \mathrm{~cm}^{-1}$. The presence of a band in the range $3700-3200 \mathrm{~cm}^{-1}$ is attributed to physically adsorbed water $(-\mathrm{OH})$ and $\mathrm{N}-\mathrm{H}$ stretching vibrations. The peak at $1620 \mathrm{~cm}^{-1}$ corresponds to deformation vibrations of free water molecules. There are also two bands at 941 and $1541 \mathrm{~cm}^{-1}$, associated with vibrational modes involving $\equiv \mathrm{Ti}-\mathrm{O}-\mathrm{Si} \equiv$ bonding. The bands at 825 and $1081 \mathrm{~cm}^{-1}$ correspond to symmetric and asymmetric stretching vibrations of the $\equiv \mathrm{Si}-\mathrm{O}-\mathrm{Si} \equiv$ group, and a band with significant intensity in the range $2965-2850 \mathrm{~cm}^{-1}$ is characteristic for stretching vibrations of C-H (Siwińska-Stefańska et al. 2017).

The FTIR spectra of the TSC hybrids (samples TSC10 and TSC30) contain characteristic signals for both the support and the chlorophyllin, with significant changes in the intensities of the bands. A broad signal in the range $3650-3350 \mathrm{~cm}^{-1}$ reflects the presence of physically adsorbed water $(-\mathrm{OH})$ and $\mathrm{N}-\mathrm{H}$ stretching vibrations. The peaks at 941 and $1541 \mathrm{~cm}^{-1}$ are attributed to $\equiv \mathrm{Ti}-\mathrm{O}-\mathrm{Si} \equiv$ bonding. The spectra of the hybrids also reveal skeletal vibrations of the porphyrin ring formed by $\mathrm{C}=\mathrm{C}$ and $\mathrm{C}=\mathrm{N}$ bonds at $1565 \mathrm{~cm}^{-1}$, as well as characteristic vibrations attributed to $\mathrm{C}-\mathrm{H}$ and $\mathrm{C}-\mathrm{C}$ around $2920 \mathrm{~cm}^{-1}$ and $1400 \mathrm{~cm}^{-1}$, which indicate that the chlorophyllin was successfully adsorbed onto the $\mathrm{TiO}_{2}-\mathrm{SiO}_{2}$ material. There is also a signal of low intensity in the range $750-570 \mathrm{~cm}^{-1}$ characteristic for the copper present in the structure of the chlorophyllin (Gong et al. 2012; Sun et al. 2013). These signals confirm the successful adsorption of chlorophyllin onto the $\mathrm{TiO}_{2}-\mathrm{SiO}_{2}$ support. Moreover, on FTIR spectra of TSC hybrids, characteristic absorption bands at 1082 and $1093 \mathrm{~cm}^{-1}$, which can be

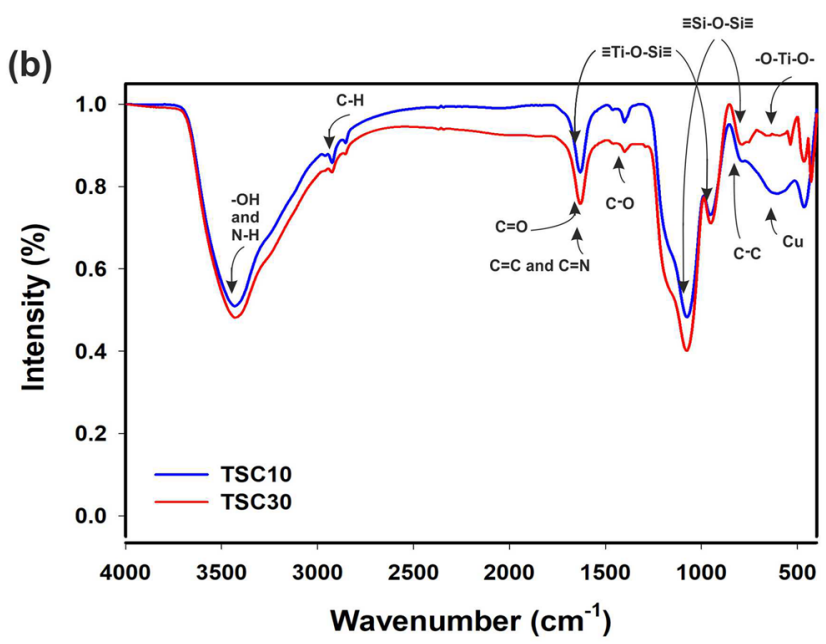

Fig. 2 FTIR spectra of: a chlorophyllin and $\mathrm{TiO}_{2}-\mathrm{SiO}_{2}$, b selected TSC hybrids 
$\mathrm{TiO}_{2}-\mathrm{SiO}_{2}$ support

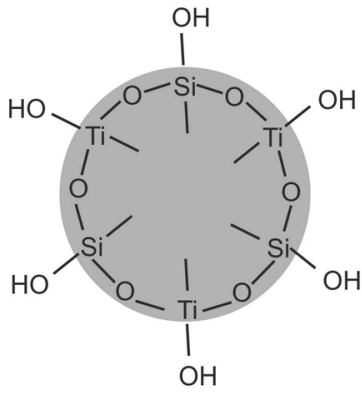

Chlorophyllin

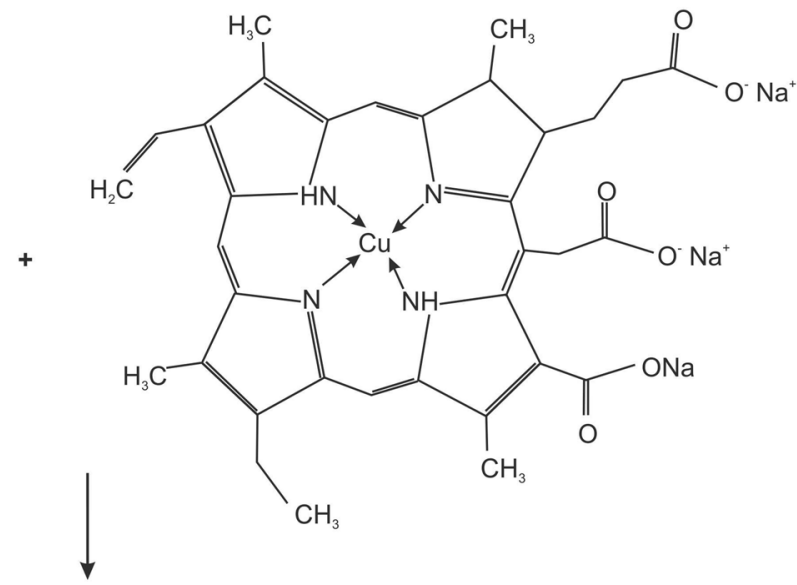

$\mathrm{TiO}_{2}-\mathrm{SiO}_{2} /$ chlorophyllin hybrid

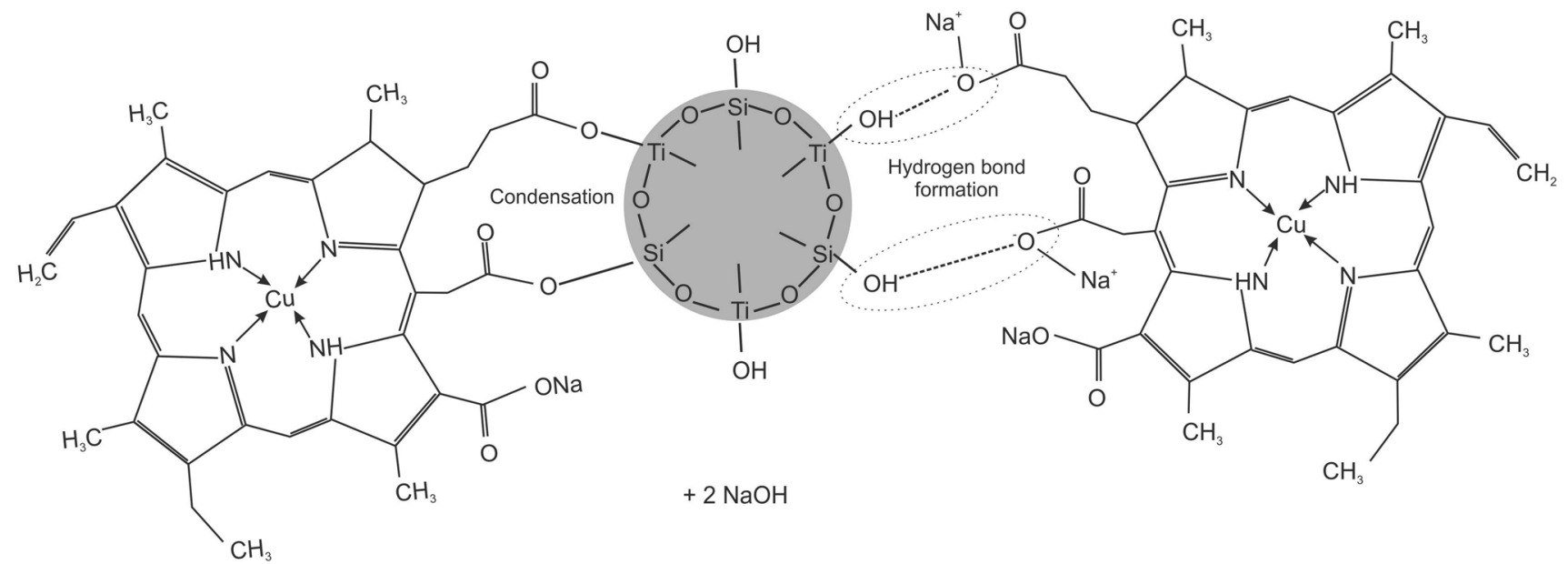

Fig. 3 Probable mechanism of formation of $\mathrm{TiO}_{2}-\mathrm{SiO}_{2} /$ chlorophyllin hybrids

ascribed to the vibration of $\mathrm{Ti}-\mathrm{O}-\mathrm{C}$ bonds, which can indicate a strong chemical interaction between the titania-silica material and chlorophyllin, may be overlap with the intense absorption bands characteristic to $\equiv \mathrm{Ti}-\mathrm{O}-\mathrm{Si} \equiv$ bonds.

Based on elemental and FTIR analysis, we propose a probable mechanism of interaction between chlorophyllin and the $\mathrm{TiO}_{2}-\mathrm{SiO}_{2}$ material (Fig. 3). We believe that hydrogen bond formation or a condensation reaction plays a key role in the adsorption of chlorophyllin onto the $\mathrm{TiO}_{2}-\mathrm{SiO}_{2}$ oxide material.

\subsection{Thermal analysis}

The effectiveness of the adsorption process was further examined by thermal analysis (TGA/DTA) of the chlorophyllin, $\mathrm{TiO}_{2}-\mathrm{SiO}_{2}$ and selected TSC hybrids (samples TSC10,
TSC20 and TSC30). Thermogravimetric curves (TGA), as well as their first derivatives (DTA), were obtained (Fig. 4).

The thermogravimetric curve for chlorophyllin, shown in Fig. 4a, indicates a three-stage degradation process. The first degradation step, in the temperature range $30-250{ }^{\circ} \mathrm{C}$, with a mass loss of about 7\%, is related to the local elimination of water bonded with the surface of the dye. Farag et al. (2012) also reported that the first loss of the mass in the chlorophyllin degradation may be related to the evaporation of residual adsorbed water. The second mass loss of about $49 \%$ in the temperature range $250-500{ }^{\circ} \mathrm{C}$, also observed by Norman et al. (2016), is associated with the elimination of $\mathrm{Cu}^{2+}$ ions. This degradation step was also mentioned by Farag et al. (2012) work. These mass changes are confirmed by clear exothermic peaks on the DTA curve (Fig. 4a). In the third stage, thermal treatment above $500^{\circ} \mathrm{C}$ (up to $1000^{\circ} \mathrm{C}$ ) causes a gradual loss of mass by a further $5 \%$, resulting 
(a)

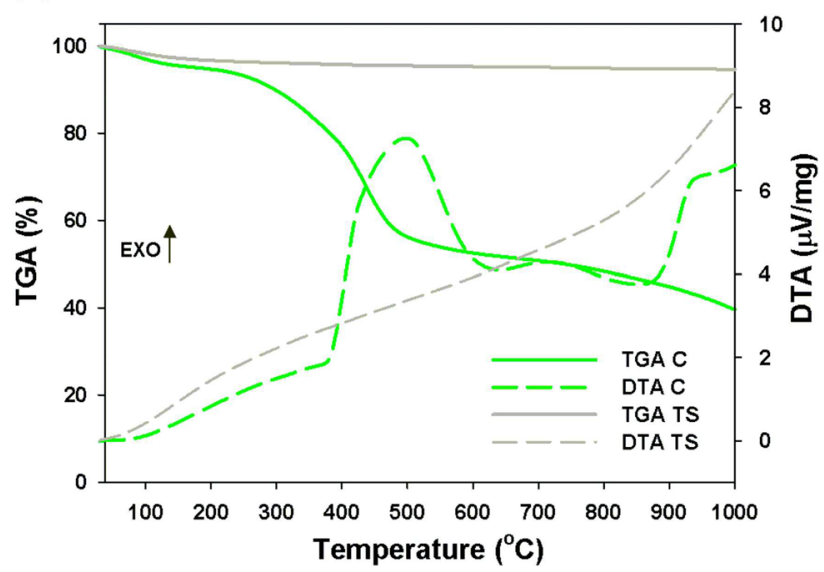

(b)

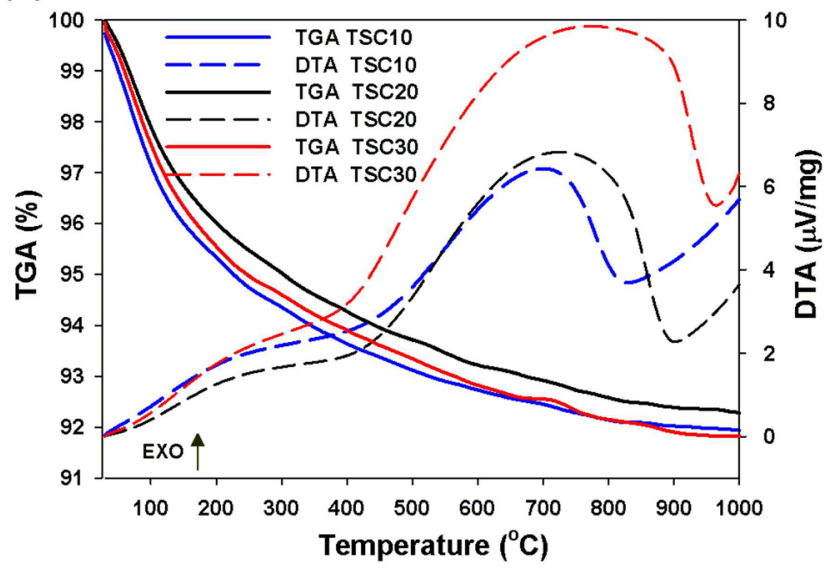

Fig. 4 Thermal stability of: a chlorophyllin and $\mathrm{TiO}_{2}-\mathrm{SiO}_{2}$, b selected TSC hybrids

from breakage and thermal decomposition of the porphyrin macrocycle.

Decomposition of the titania-silica material begins as low as $30^{\circ} \mathrm{C}$ and occurs in a single step. The mass loss observed in the range $30-280{ }^{\circ} \mathrm{C}$ is rather abrupt. Above $280{ }^{\circ} \mathrm{C}$ the sample stabilizes and its mass remains almost unchanged. Over the temperature range $30-1000{ }^{\circ} \mathrm{C}$ sample TS loses only $6.0 \%$ of its total mass.

The TGA curves of the TSC10, TSC20 and TSC30 hybrids (Fig. 4b) show small mass losses of approximately 8.1\% (sample TS10), 7.8\% (sample TSC20) and 8.2\% (sample TSC30) in the temperature range $30-1000{ }^{\circ} \mathrm{C}$. This is related to the presence of a small amount of moisture in the systems. The visible endothermic effect recorded in the DTA curve (Fig. 4b) is a confirmation of the changes occurring and the transformation of anatase to the rutile form of titanium dioxide.

\subsection{Kinetic studies of adsorption}

An investigation of the adsorption kinetics for chlorophyllin was performed using model solutions at concentrations of 25,50 , and $100 \mathrm{mg} / \mathrm{dm}^{3}$. The kinetics of the adsorption process were determined using pseudo-first-order (Lagergren 1898) and pseudo-second-order (Ho and McKay 1999) models.

Analysis of the parameters obtained using the pseudofirst-order model shows that this model provides only a fair description of the experimental data. The obtained results are presented in detail in Supplementary Material (see Fig. S2).

A far better fit to the experimental data was achieved using the pseudo-second-order kinetic model (Fig. 5). The correlation coefficient $\left(r^{2}\right)$ calculated for this model was 0.999 for all analyzed dye concentrations $(25-100 \mathrm{mg} /$ $\left.\mathrm{dm}^{3}\right)$. Also the values computed using this model $\left(q_{e, c a l}\right)$

\begin{tabular}{|c|c|c|c|c|c|}
\hline \multirow{3}{*}{ Kinetic model } & \multicolumn{2}{|c|}{ Parameters } & \multicolumn{3}{|c|}{$\begin{array}{c}\text { Concentration } \\
\text { of chlorophyllin } \\
\left(\mathbf{m g} / \mathbf{d m}^{3}\right)\end{array}$} \\
\hline & symbol & unit & 25 & 50 & 100 \\
\hline & $q_{\theta, c a l}$ & $\mathrm{mg} / \mathrm{g}$ & 2.38 & 4.84 & 9.36 \\
\hline \multirow{3}{*}{$\begin{array}{c}\text { Pseudo- } \\
\text { second-order }\end{array}$} & $k_{2}$ & $\begin{array}{l}\mathrm{g} / \mathrm{mg} \\
\min \end{array}$ & 0.625 & 0.197 & 0.335 \\
\hline & $h$ & $\underset{\mathrm{min}}{\mathrm{mg} / \mathrm{g}}$ & 3.55 & 4.62 & 29.35 \\
\hline & $r^{2}$ & - & 0.999 & 0.999 & 0.999 \\
\hline
\end{tabular}

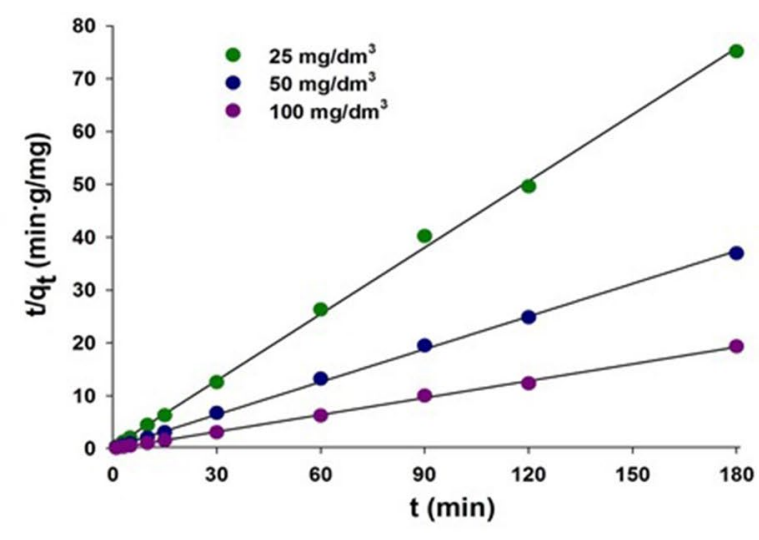

Fig. 5 Pseudo-second-order kinetic parameters and fit for chlorophyllin adsorption onto $\mathrm{TiO}_{2}-\mathrm{SiO}_{2}$ 
Table 6 Examples of application of pseudosecond-order model for the determination of kinetic aspects of the chlorophyllin adsorption

\begin{tabular}{lllll}
\hline Adsorbent & $\begin{array}{l}\text { Dye concentration } \\
\left(\mathrm{mg} / \mathrm{dm}^{3}\right)\end{array}$ & $r^{2}(-)$ & $k_{2}(\mathrm{~g} / \mathrm{mg} \mathrm{min})$ & References \\
\hline H. communis & 100 & 0.999 & 0.102 & Norman et al. (2016) \\
sponge skeletons & 200 & 0.997 & 0.010 & \\
& 300 & 0.999 & 0.009 & Hou et al. (2012) \\
Silk & 300 & 0.999 & 0.014 & This study \\
& & 0.999 & 0.020 & \\
$\mathrm{TiO}_{2}-\mathrm{SiO}_{2}$ & 25 & 0.999 & 0.625 & \\
& 50 & 0.999 & 0.197 & \\
& 100 & 0.999 & 0.335 & \\
\hline
\end{tabular}

corresponded to the experimental data $\left(q_{e, \text { exp }}\right)$. There was found to be a rise in the initial adsorption rate $(h)$ as the initial concentration of dye increased.

Other researchers have also determined the kinetics of chlorophyllin adsorption using selected adsorbents. The kinetic parameters obtained by them are listed in Table 6. It is important to determine adsorption kinetics to facilitate monitoring of the effectiveness of dye adsorption from aqueous solutions. The adsorption of chlorophyllin using various materials is described in most cases by the pseudo-secondorder model.

\subsection{Photocatalytic activity}

The photocatalytic activities of selected $\mathrm{TiO}_{2}-\mathrm{SiO}_{2}$ /chlorophyllin hybrids (samples TSC10 and TSC30) were evaluated based on the decomposition of C.I. Basic Violet 10 in aqueous solution under UV irradiation. The results are presented in Fig. 6.

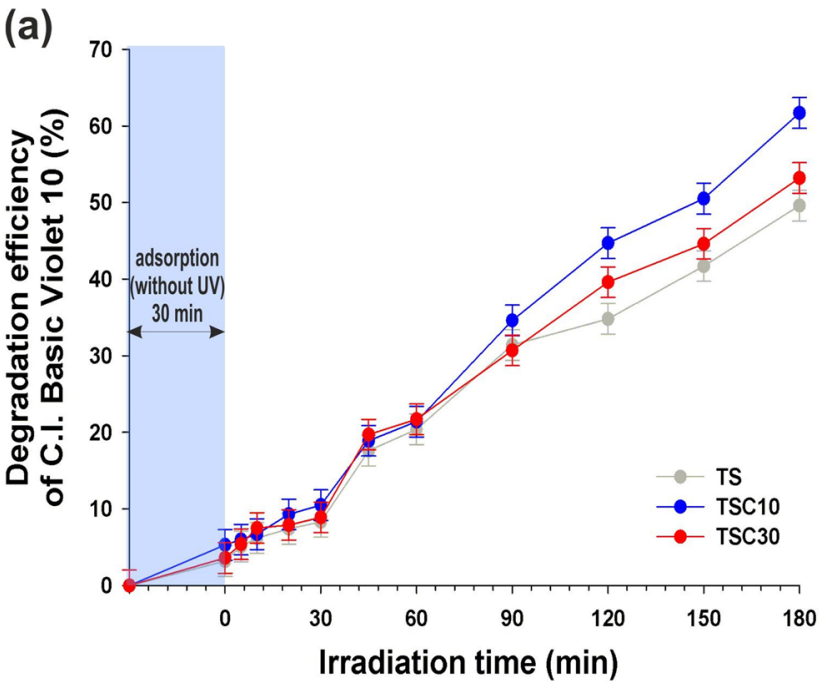

The results show that the photocatalytic decomposition of C.I. Basic Violet 10 in the presence of the obtained hybrid materials increased with increasing irradiation time (Fig. 6). Sample TS exhibited the lowest photocatalytic activity in the degradation of C.I. Basic Violet 10, with a photocatalytic efficiency of $49.6 \%$ (after $180 \mathrm{~min}$ of UV irradiation). Better photocatalytic activity (53.2\%) was obtained with sample TSC30. The highest efficiency of C.I. Basic Violet 10 decomposition was recorded in the presence of sample TSC10, obtained by adsorption of chlorophyllin from a solution with a concentration of $25 \mathrm{mg} / \mathrm{dm}^{3}$ : after $180 \mathrm{~min}$ of UV irradiation, $61.7 \%$ of the dye was decomposed.

The second stage of photocatalytic testing involved evaluation of the photocatalytic activity of TS and TSC hybrids in the removal of C.I. Basic Violet 10 in the presence of $\mathrm{H}_{2} \mathrm{O}_{2}$ (Fig. 6b). For these experiments, $\mathrm{H}_{2} \mathrm{O}_{2}$ was added to the aqueous suspension of dye at the start of light irradiation. The addition of hydrogen peroxide to the reaction system leads to increased decomposition efficiency of the dye, in

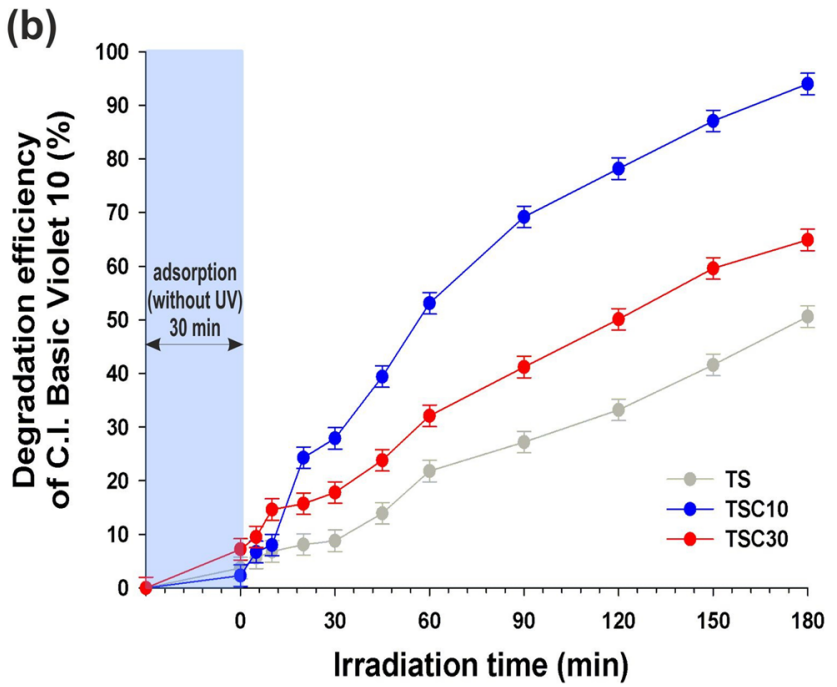

Fig. 6 Efficiency of photocatalytic decomposition of C.I. Basic Violet 10 in the presence of the synthesized hybrids: a without $\mathrm{H}_{2} \mathrm{O}_{2}$ and $\mathbf{b}$ with $\mathrm{H}_{2} \mathrm{O}_{2}$ 
the case of all of the materials used. The degradation of C.I. Basic Violet 10 under UV irradiation showed that sample TS, in the presence of $\mathrm{H}_{2} \mathrm{O}_{2}$, had better photo-oxidation activity (the efficiency of its degradation of the dye was $50.6 \%$ after $180 \mathrm{~min}$ ) than the TS photocatalyst without the addition of hydrogen peroxide (49.6\%). The slight improvement in the photocatalytic activity observed for the TS sample in the presence of hydrogen peroxide can be attributed to the synergic effect between the photocatalyst and $\mathrm{H}_{2} \mathrm{O}_{2}$. However, the photodegradation of C.I. Basic Violet 10 by samples TSC10 and TSC30 is greatly accelerated by the addition of hydrogen peroxide, leading to efficiencies of $94.0 \%$ and $64.9 \%$ respectively. These results show that the addition of hydrogen peroxide plays a significant role in the degradation of the dye. The higher photocatalytic degradation after the addition of $\mathrm{H}_{2} \mathrm{O}_{2}$ was attributed to the increase in the concentration of hydroxyl radicals. Most studies have shown that the rates and efficiencies of photo-assisted degradation of organic substrates are significantly improved in the presence of peroxides (Daneshvar et al. 2002; Bauer et al. 1999; Fox and Dulag 1993), because hydrogen peroxide inhibits electron-hole recombination. Moreover, hydrogen peroxide is a better electron acceptor than molecular oxygen, and can act as an alternative electron acceptor to oxygen (Daneshvar et al. 2003; Khodja et al. 2001). Other studies have demonstrated that copper(II) porphyrins exhibit enhanced photocatalytic efficiency in sensitizing $\mathrm{TiO}_{2}$ for the photodegradation of organic pollutants. Sun et al. (2013) demonstrated that hydrogen peroxide added to the reaction mixture reacts directly with photoinduced electrons to produce hydroxyl radicals, and can then lead to the generation of hydroxyl radicals, which are a powerful oxidizing agent capable of photodegrading C.I. Basic Violet 10 into small molecules or $\mathrm{CO}_{2}$ and $\mathrm{H}_{2} \mathrm{O}$. We propose the following steps for the degradation of C.I. Basic Violet 10 in the presence of $\mathrm{TiO}_{2}-\mathrm{SiO}_{2} /$ chlorophyllin hybrids.

$$
\begin{aligned}
& \mathrm{TiO}_{2}-\mathrm{SiO}_{2}+h v \rightarrow \mathrm{TiO}_{2}-\mathrm{SiO}_{2}\left(e^{-}+h^{+}\right) \\
& \mathrm{Ch} \text { lorophyllin }+h v \rightarrow \text { Chlorophyllin }\left(e^{-}+h^{+}\right) \\
& \mathrm{TiO}_{2}-\mathrm{SiO}_{2}\left(e^{-}\right)+\mathrm{O}_{2} \rightarrow \mathrm{TiO}_{2}-\mathrm{SiO}_{2}+{ }^{*} \mathrm{O}_{2}^{-} \\
& { }^{*} \mathrm{O}_{2}^{-}+2 \mathrm{H}^{+} \rightarrow \mathrm{H}_{2} \mathrm{O}_{2} \\
& \mathrm{TiO}_{2}-\mathrm{SiO}_{2}\left(e^{-}\right)+\mathrm{H}_{2} \mathrm{O}_{2} \rightarrow \mathrm{TiO}_{2}-\mathrm{SiO}_{2}+\mathrm{OH}^{*}+\mathrm{OH}^{-} \\
& \mathrm{TiO}_{2}-\mathrm{SiO}_{2}\left(h^{+}\right)+\mathrm{OH}^{-} \rightarrow \mathrm{TiO}_{2}-\mathrm{SiO}_{2}{ }^{-}+\mathrm{OH}^{*} \\
& \left.\mathrm{Chlorophyllin}^{*} h^{+}\right)+\mathrm{OH}^{-} \rightarrow \mathrm{Chlorophyllin}+\mathrm{OH}^{*} \\
& { }^{*} \mathrm{O}_{2}^{-}+\text {dye } \rightarrow \text { decomposition products } \\
& \text { OH }+ \text { dye } \rightarrow \text { decomposition products }
\end{aligned}
$$

$\mathrm{HO}_{2}{ }^{*}+$ dye $\rightarrow$ decomposition products

\subsection{Kinetic studies of photocatalysis}

Analysis of the kinetics of photocatalytic degradation of C.I. Basic Violet 10 shows a significantly differences in the rate of decomposition of the analyzed pollutant in the presence of the used catalysts (Table 7). Heterogeneous photodegradation of C.I. Basic Violet 10 in the presence of a TSC10 photocatalyst was characterized by the highest value of rate constant of reaction, which amounted to $0.0053 \mathrm{~min}^{-1}$. The used catalyst was also characterized by the shortest half-life time (130 min). In the case of the TS sample, a more than $71 \%$ decrease of rate constant reaction $\left(0.0038 \mathrm{~min}^{-1}\right)$ is observed compared to the TSC10 photocatalyst. Moreover, the use of TS catalyst contributed to the extension of time $t_{1 / 2}$ (182.09 $\mathrm{min}$ ) relative to the TSC sample. The effect of the addition of hydrogen peroxide was also investigated on the constant rate of reaction of photochemical decomposition of C.I. Basic Violet 10 in the presence of used catalysts. The results show that highest value of the degradation rate $k$ was recorded when TSC10 catalyst was used as a photocatalyst. Moreover, in the presence of TSC sample also the higher value of the half-life time (44.35 $\mathrm{min}$ ) of rested organic dye was noted.

\section{Conclusions}

It has been shown that the proposed sol-gel methodology for the synthesis of a $\mathrm{TiO}_{2}-\mathrm{SiO}_{2}$ oxide material is very efficient

\begin{tabular}{|c|c|c|c|}
\hline Sample & $k(1 / \min )$ & $R^{2}$ & $t_{1 / 2}(\min )$ \\
\hline \multicolumn{4}{|c|}{ C.I. Basic Violet 10} \\
\hline TS & 0.0038 & 0.9888 & 182.09 \\
\hline TSC10 & 0.0053 & 0.9866 & 130.00 \\
\hline TSC30 & 0.0042 & 0.9908 & 164.32 \\
\hline \multicolumn{4}{|c|}{ C.I. Basic Violet $10+\mathrm{H}_{2} \mathrm{O}_{2}$} \\
\hline TS & 0.0039 & 0.9850 & 176.92 \\
\hline TSC10 & 0.0156 & 0.9817 & 44.35 \\
\hline TSC30 & 0.0058 & 0.9836 & 119.17 \\
\hline
\end{tabular}
and leads to a material with strictly defined physicochemical and structural parameters-monomodal particle size distribution, almost spherical particle shape and designed crystalline and porous structure-which favor its use as an adsorbent of chlorophyllin.

Table 7 The reaction rate constant $(k)$, correlation coefficient $\left(R^{2}\right)$ and half-life time $\left(t_{1 / 2}\right)$ of C.I. Basic Violet 10 during photocatalytic process 
Studies of the adsorption of chlorophyllin onto the titania-silica oxide system have proved that functional groups present on the synthetic oxide material show high affinity to functional groups occurring in the structure of the chlorophyllin. The adsorption efficiency of chlorophyllin onto $\mathrm{TiO}_{2}-\mathrm{SiO}_{2}$ oxide material is over $90 \%$, independent of the initial chlorophyllin concentration. Moreover, the hybrids obtained by adsorption of chlorophyllin on inorganic oxide material were relatively stable. The kinetics of the chlorophyll adsorption process are precisely described by the pseudo-second-order kinetic model, which will significantly facilitate its design on an industrial scale.

The results of EA, surface composition (EDS) and FTIR analysis indirectly confirm the effectiveness of the adsorption process.

Thermogravimetric analysis of the $\mathrm{TiO}_{2}-\mathrm{SiO}_{2}$ /chlorophyllin hybrids showed a significant improvement in the thermal stability of the obtained material compared with the original chlorophyllin.

The $\mathrm{TiO}_{2}-\mathrm{SiO}_{2} /$ chlorophyllin hybrids exhibit good photocatalytic activity in the decomposition of C.I. Basic Violet 10. It was also shown that the addition of hydrogen peroxide results in an increase in the efficiency of degradation of the dye.

Moreover, analysis of the kinetics of the photocatalytic process performed based on the Langmuir-Hinshelwood equation confirmed that degradation of C.I. Basic Violet 10 occurred most intensely in the presence of the TSC10 catalyst.

Acknowledgements This research was funded by Ministry of Science and Higher Education (Poland) as financial subsidy to PUT.

Funding Funding was provided by Politechnika Poznańska.

Open Access This article is distributed under the terms of the Creative Commons Attribution 4.0 International License (http://creativeco mmons.org/licenses/by/4.0/), which permits unrestricted use, distribution, and reproduction in any medium, provided you give appropriate credit to the original author(s) and the source, provide a link to the Creative Commons license, and indicate if changes were made.

\section{References}

Barea, E.M., Bisquert, J.: Properties of chromophores determining recombination at the $\mathrm{TiO}_{2}$-dye-electrolyte interface. Langmuir 29, 8773-8781 (2013)

Bauer, R., Waldner, G., Fallmann, H., Hager, S., Klare, M., Krutzler, T., Malato, S., Maletzky, P.: The photo-Fenton reaction and the $\mathrm{TiO}_{2} / \mathrm{UV}$ process for waste water treatment: novel developments. Catal. Today 53, 131-144 (1999)

Berendsen, G.E., de Golan, L.: Preparation and chromatographic properties of some chemically bonded phases for reversed-phase liquid chromatography. J. Liq. Chromatogr. 1, 561-586 (1978)
Braun, J.H.: Titanium dioxide: a review. J. Coat. Technol. 69, 59-72 (1997)

Chen, X., Mao, S.S.: Titanium dioxide nanomaterials: synthesis, properties, modifications, and applications. Chem. Rev. 107, 28912959 (2007)

Daneshvar, N., Salary, D., Behnasuady, M.A.: Decomposition of anionic sodium dodecylbenzene sulfonate by $\mathrm{UV} / \mathrm{TiO}_{2}$ and $\mathrm{UV} / \mathrm{H}_{2} \mathrm{O}_{2}$ processes a comparison of reaction rates. Iran. J. Chem. Chem. Eng. 21, 55-62 (2002)

Daneshvar, N., Salari, D., Khataee, A.R.: Photocatalytic degradation of azo dye acid red 14 in water: investigation of the effect of operational parameters. J. Photochem. Photobiol. A 157, 111-116 (2003)

Delsouz Khaki, M.R., Shafeeyan, M.S., Raman, A.A.A., Daud, W.M.A.W.: Evaluating the efficiency of nano-sized $\mathrm{Cu}$ doped $\mathrm{TiO}_{2} / \mathrm{ZnO}$ photocatalyst under visible light irradiation. J. Mol. Liq. 258, 354-365 (2018)

Du, X., Men, K., Xu, Y., Li, B., Yang, Z., Liu, Z., Li, L., Li, L., Feng, T., ur Rehman, W., Ullah, I., Mao, S.: Enhanced capacitance perfomance of $\mathrm{Al}_{2} \mathrm{O}_{3}-\mathrm{TiO}_{2}$ composite thin film via sol-gel using double chelators. J. Colloid Interface Sci. 443, 170-176 (2015)

Farag, A.A., Mansour, A.M., Ammar, A.H., Rafea, M.A., Farid, A.M.: Electrical conductivity, dielectric properties and optical absorption of organic based nanocrystalline sodium copper chlorophyllin for photodiode application. J. Alloys Compd. 513, 404-413 (2012)

Fox, M.A., Dulag, M.T.: Heterogeneous photocatalysis. Chem. Rev. 93, 41-57 (1993)

Fujishima, A., Zhang, X., Tryk, D.A.: $\mathrm{TiO}_{2}$ photocatalysis and related surface phenomena. Surf. Sci. Rep. 63, 515-582 (2008)

Garmaroudi, Z.A., Mohammadi, M.R.: Design of $\mathrm{TiO}_{2}$ dye-sensitized solar cell photoanode electrodes with different microstructures and arrangement modes of the layers. J. Sol-Gel. Sci. Technol. 76, 666-678 (2015)

Gong, J., Pu, W., Yang, Ch, Zhang, J.: Tungsten and nitrogen co-doped $\mathrm{TiO}_{2}$ electrode sensitized with Fe-chlorophyllinfor visible light photoelectrocatalysis. Chem. Eng. J. 209, 94-101 (2012)

He, Y., Fu, Z., Zhou, Q., Zhong, M., Yuan, L., Wei, J., Yang, X., Zeng, W.Ch: Y.: Fabrication and electrochemical behavior of a lithiumsulfur cell with a $\mathrm{TiO}_{2}$-sulfur-carbon aerogel-based cathode. Ionics 21, 3065-3073 (2015)

Ho, Y.S., McKay, G.: Pseudo-second order model for sorption processes. Process Biochem. 34, 451-465 (1999)

Hou, X., Yang, R., Xu, H., Yang, Y.: Adsorption kinetic and thermodynamic studies of silk dyed with sodium copper chlorophyllin. Ind. Eng. Chem. Res. 51, 8341-8347 (2012)

Joshi, M., Kamble, S.P., Labhsetwar, N.K., Parwate, D.V., Rayalu, S.S.: Chlorophyll-based photocatalysts and their evaluations for methyl orange photoreduction. J. Photochem. Photobiol. A Chem. 204, 83-89 (2009)

Khodja, A.A., Sehili, T., Pihichowski, J.F., Boule, P.: Photocatalytic degradation of 2-phenylphenol on $\mathrm{TiO}_{2}$ and $\mathrm{ZnO}$ in aqueous suspensions. J. Photochem. Photobiol. A 141, 231-239 (2001)

Krishnakumar, B., Balakrishna, A., Arranja, C.T., Dias, C.M.F., Sobra, A.J.F.N.: Chemically modified amino porphyrin/ $/ \mathrm{TiO}_{2}$ for the degradation of Acid Black 1 under day light illumination. Spectrochim. Acta A. Mol. Biomol. Spectrosc. 176, 134-141 (2017)

Kruk, M., Jaroniec, M.: Gas adsorption characterization of ordered organic-inorganic nanocomposite materials. Chem. Mater. 13, 3169-3183 (2001)

Kumar, S.G., Rao, K.S.R.K.: Comparison of modification strategies towards enhanced charge carrier separation and photocatalytic degradation activity of metal oxide semiconductors $\left(\mathrm{TiO}_{2}, \mathrm{WO}_{3}\right.$ and ZnO). Appl. Surf. Sci. 391, 124-148 (2017)

Lagergren, S.: About the theory of so-called adsorption of soluble substances. Kungl Svenska Vetensk Hand 24, 1-39 (1898) 
Lüa, X.-F., Qian, H., Mele, G., De Riccardis, A., Zhao, R., Chen, J., Wu, H., Hud, N.-J.: Impact of different $\mathrm{TiO}_{2}$ samples and porphyrin substituents on the photocatalytic performance of $\mathrm{TiO}_{2} @$ copper porphyrin composites. Catal. Today 281, 45-52 (2017)

Messina, P.V., Morini, M.A., Sierra, M.B., Schulz, P.B.: Mesoporous silica-titania composed materials. J. Colloid Interf. Sci. 300, 270-278 (2006)

Michalow, K.A., Otal, E.H., Burnat, D., Fortunato, G., Emerich, H., Ferri, D., Heel, A., Graule, T.: Flame-made visible light active $\mathrm{TiO}_{2}: \mathrm{Cr}$ photocatalysts: correlation between structural, optical and photocatalytic properties. Catal. Today 209, 47-53 (2013)

Mohamed, M.M., Salama, T.M., Yamaguchi, T.: Synthesis, characterization and catalytic properties of titania-silica catalysts. Colloids Surf. A 207, 25-32 (2002)

Nilchi, A., Janitabar-Darzi, S., Mahjoub, A.R., Rasouli-Garmarodi, S.: New $\mathrm{TiO}_{2} / \mathrm{SiO}_{2}$ nanocomposites-Phase transformations and photocatalytic studies. Colloids Surf. A 361, 25-30 (2010)

Nolan, M., Iwaszuk, A., Lucid, A.K., Carey, J.J., Fronzi, M.: Design of novel visible light active photocatalyst materials: surface modified $\mathrm{TiO}_{2}$. Adv. Mater. 28, 5425-5446 (2016)

Norman, M., Bartczak, P., Zdarta, J., Tomala, W., Żurańska, B., Dobrowolska, A., Piasecki, A., Czaczyk, K., Ehrlich, H., Jesionowski, T.: Sodium copper chlorophyllin immobilization onto Hippospongia communis marine demosponge skeleton and its antibacterial activity. Int. J. Mol. Sci. 17, 1564-1580 (2016)

Park, J.-H., Jang, I., Song, K., Oh, S.-G.: Surfactants-assisted preparation of $\mathrm{TiO}_{2}-\mathrm{Mn}$ oxide composites and their catalytic activities for degradation of organic pollutant. J. Phys. Chem. Solids 74, 1056-1062 (2013)

Phongamwong, T., Donphai, W., Prasitchoke, P., Rameshan, Ch, Barrabeis, N., Klysubun, W., Rupprechter, G., Chareonpanich, M.: Novel visible-light-sensitized Chl- $\mathrm{Mg} / \mathrm{P} 25$ catalysts for photocatalyticdegradation of rhodamine B. Appl. Catal. B 207, 326-334 (2017)

Pirzada, B.M., Mir, N.A., Qutub, N., Mehraj, O., Sabir, S., Muneer, M.: Synthesis, characterization and optimization of photocatalytic activity of $\mathrm{TiO}_{2} / \mathrm{ZrO}_{2}$ nanocomposite heterostructures. Mater. Sci. Eng. B-Solid. 193, 137-145 (2015)
Pouretedal, H.R.: Visible photocatalytic activity of co-doped $\mathrm{TiO}_{2} / \mathrm{Zr}, \mathrm{N}$ nanoparticles in wastewater treatment of nitrotoluene samples. J. Alloys Compd. 735, 2507-2511 (2018)

Siwińska-Stefańska, K., Szwarc-Rzepka, K., Piasecki, A., Jesionowski, T.: Nano- $-\mathrm{TiO}_{2}-\mathrm{SiO}_{2}$ powder as inorganic support for hybrid pigment preparation. Adv. Powder Technol. 28, 1298-1308 (2017)

Soltan, S., Jafari, H., Afshar, S., Zabihi, O.: Enhancement of photocatalytic degradation of furfural and acetophenone in water media using nano- $\mathrm{TiO}_{2}-\mathrm{SiO}_{2}$ deposited on cementitious materials. Water Sci. Technol. 74, 1689-1697 (2016)

Sun, W.-J., Li, J., Mele, G., Zhang, Z.-Q., Zhang, F.-X.: Enhanced photocatalytic degradation of rhodamine $\mathrm{B}$ by surface modification of $\mathrm{ZnO}$ with copper(II) porphyrin under both UV-Vis and visible light irradiation. J. Mol. Catal. A 36, 84-91 (2013)

Tobaldi, D.M., Tucci, A., Ŝkapin, A.S., Esposito, L.: Effects of $\mathrm{SiO}_{2}$ addition on $\mathrm{TiO}_{2}$ crystal structure and photocatalytic activity. J. Eur. Ceram. Soc. 30, 2481-2490 (2010)

Vebber, M.C., Faria, A.C.R., Dal'Acqua, N., Beal, L.L., Fetter, G., Machado, G., Giovanela, M., Crespo, J.S.: Hydrogen production by photocatalytic water splitting using poly(allylamine hydrochloride)/poly(acrylic acid)/ $/ \mathrm{TiO}_{2} /$ copper chlorophyllin selfassembled thin films. Int. J. Hydrogen Energy 41, 17995-18004 (2016)

Wang, S.Q., Liu, W.B., Fu, P., Cheng, W.L.: Enhanced photoactivity of $\mathrm{N}$-doped $\mathrm{TiO}_{2}$ for $\mathrm{Cr}(\mathrm{VI})$ removal: Influencing factors and mechanism. Korean J. Chem. Eng. 34, 1584-1590 (2017)

Winkler, J.: Titanium Dioxide. Production, Properties and Effective Usage, 2nd edn. Vincentz Network, Hanover (2013)

Wu, Z.Y., Tao, Y.F., Lin, Z., Liu, L., Fan, X.X., Wang, Y.: Hydrothermal synthesis and morphological evolution of mesoporous titaniasilica. J. Phys. Chem. C 113, 20335-20348 (2009)

Publisher's Note Springer Nature remains neutral with regard to jurisdictional claims in published maps and institutional affiliations.

\section{Affiliations}

\section{Katarzyna Siwińska-Ciesielczyk ${ }^{1} \cdot$ Olga Bartlewicz $^{1,2} \cdot$ Przemysław Bartczak $^{1} \cdot$ Adam Piasecki $^{3} \cdot$ Teofil Jesionowski $^{1}$}

Katarzyna Siwińska-Ciesielczyk

katarzyna.siwinska-ciesielczyk@put.poznan.pl

1 Faculty of Chemical Technology, Institute of Chemical Technology and Engineering, Poznan University of Technology, Berdychowo 4, 60965 Poznan, Poland

2 Faculty of Chemistry, Adam Mickiewicz University in Poznan, Umultowska 89b, Poznan, Poland
3 Faculty of Mechanical Engineering and Management, Institute of Materials Science and Engineering, Poznan University of Technology, Jana Pawla II 24, 60965 Poznan, Poland 